\title{
Oocyte Developmental Stages and its R elationship with the Zona Layers During Vitellogenesis in theAsian Striped Catfish M ystus vittatus (Bloch, 1794)
}

\author{
Nilanjana Chatterjee ${ }^{1}$ and Baibaswata Bhattacharjee ${ }^{2^{*}}$ \\ ${ }^{1}$ Department of Zoology, Ramananda College, Bishnupur, Bankura-722 122, India. \\ ${ }^{2}$ Department of Physics, Ramananda College, Bishnupur, Bankura-722 122, India.
}

\section{ARTICLE INFO \\ Article history: \\ Received on: 01/06/2014 \\ Revised on: 22/06/2014 \\ Accepted on: 14/07/2014 \\ Available online: 27/08/2014}

Key words:

Zona granulosa, Zona

radiata, Vitellogenesis,

Oocyte, Mystus vittatus

\begin{abstract}
Statistical analysis and size distribution study on oocytic cells during vitellogenesis of the Asian striped catfish Mystus vittatus were performed systematically to gather useful information required for aquaculture of this economically important fish in south-east Asia. Mean oocytic cell diameters were found to increase with advancement of vitellogenic stages. Semi quantitative approach is employed to establish relationships between Oocyte cell diameters with the heights of zona granulosa and zona radiata layers during vitellogenesis of $M y s t u s$ vittatus. Heights of both the layers are found to increase with oocytic cells diameters and showed linear dependence in the experimental range. It is also found that the change in the height of zona radiata with the height of zona granulosa during vitellogenesis follow non linear pattern and the data fitted well with exponential growth curve.
\end{abstract}

\section{INTRODUCTION}

The cellular zona granulosa $(\mathrm{ZG})$ and the acellular zona radiata $(\mathrm{ZR})$ form two vital layers of the oocytes in teleost fishes. These two layers act as interfaces for the transport of essential materials into and out of the cell. Our histological study reveals the appearance and growth of these two layers in the oocytes of Mystus vittatus during the process of vitellogenesis.

The oocyte development stages of the teleosts have been studied by many authors [1-8] and the main criteria used to determine the stages included the deposition of the vitellogenin and the change in characters of the surrounding acellular and cellular layers. The oocytes of teleost fishes are composed of a zona radiata (ZR) layer lying just above the oolemma. Surrounding the ZR lay the inner follicular layer or zona granulosa $(\mathrm{ZG})$. These two layers play vital role for the teleosts, as the $\mathrm{ZG}$ is involved in the process of vitellogenesis, steroidogenesis, transfer of small molecules through communicating junctions inside the oocytes, etc. [9] and the ZR bearing pore canals also play vital role in embryonic development, fertilization and interactions between the egg and its aquatic environment [10]. In our present study we have made an attempt to study the histological changes and establish

\footnotetext{
* Corresponding Author

Email:baib23@gmail.com

Tel: $+91-9832703096$
}

quantitative relationships between the heights of zona layers and the oocyte cell diameters undergoing vitellogenesis for the first time in the Asian striped catfish, Mystus vittatus, a fish having great demand in the Asian market due to its great palatability and high nutritional value [11].

\section{MATERIALS AND METHODS}

\subsection{Specimen collection}

Adult female Mystus vittatus (Bloch) were collected every month throughout the year from a particular stocking pond located in Burdwan district of West Bengal, India, in order to avoid ecological variations in different ponds that can affect ovarian development. About 186 female fishes with body weight between $21 \mathrm{~g}$ to $48 \mathrm{~g}$ were dissected for our experimental purpose.

\subsection{Histological methods and staining}

The ovary was dissected out and cut into small pieces and then fixed in aqueous Bouin's fluid [12] for 18 hours. The fixed tissues were then dehydrated, embedded in paraffin (melting point $-56{ }^{0} \mathrm{C}-58{ }^{0} \mathrm{C}$ ) and sectioned at $4 \mu \mathrm{m}$ thickness. The sections were stained with the iron-alum haematoxylin and haematoxylineosin method [12]. The stained sections were mounted permanently with DPX and examined under binocular microscope. 


\subsection{Histological measurements and statistical analysis}

From the histological preparation of the ovaries, the diameters of the various oocytic cells $(\delta)$ and the heights of the ZR $\left(\zeta_{\mathrm{ZR}}\right)$ and $\mathrm{ZG}\left(\zeta_{\mathrm{ZG}}\right)$ were measured with the help of reticulomicrometer and ocular micrometer at four points within each cell at $90^{\circ}$ from one another at a resolution of $\pm 2 \mu \mathrm{m}$. Statistical analysis and curve fitting involving the data of $\delta, \zeta_{\mathrm{ZR}}$ and $\zeta_{\mathrm{ZG}}$ are done using the software Origin 9.1.

\section{RESULT AND DISCUSSION}

\subsection{Histological observations}

Based on histological parameters, four stages of oocytic cells were identified [13] and taken into account for our purpose. The height of the ZG and ZR were found to change with the stages of oocytes as shown in the optical micrograph of the histological section of the ovaries (Figs.1, 2, 3a, 3b, 4a, 4b). The zona layer i.e. $\mathrm{ZR}$ was visible for first time during the late perinucleolus stage (Fig.1). The cells of the ZG layer increased in dimension along with the appearance of prominent nuclei (Figs. 2, 3b and 4b), in concert with the increase in oocytic diameters. Under the light microscope no such cells were identified for the ZR, however, some undulations may be observed and a rise in its height was also noticed (Figs. 2, 3b, 4b). Many authors [14, 15] have found striated structures in the zona radiata during early vitellogenesis and referred these structures as pore canals open at both the ends.

\subsection{Statistical analysis}

Data acquired from histometric studies can be used for quantitative analysis on oocyte development in different vitellogenic stages. The summary of the findings on oocyte cell measurements using histological micrographs is shown in Table I, which exhibits the maximum and minimum oocyte cell diameters recorded for each stage. Statistical analysis is employed to calculate the mean cell diameter using cell diameter data $(\mathrm{N}=50)$ recorded for different stages. It can be noticed that the mean cell height increased from $91.9 \pm 1.31 \mu \mathrm{m}$ in late perinucleolus state to $185.14 \pm 2.35 \mu \mathrm{m}$ in yolk vescicle stage then $416.25 \pm 4.73 \mu \mathrm{m}$ to yolk granule stage and finally reached to $556.98 \pm 2.72 \mu \mathrm{m}$ in matured oocyte stage. The increase in mean oocyte cell diameter with advancement in vitellogenesis can be attributed to the hydration of the maturing oocyte and incorporation of the yolk materials and some supplementary factors from the ZG through the porous ZR.

\subsection{Size distribution of oocytes during different vitellogenic stages}

Figure 5 shows the size distribution of oocytes during different vitellogenic stages. The frequency distribution data for oocyte cell diameter $(\delta)$ is fitted to the Gaussian distribution curve

$$
f(\delta)=\frac{A}{w \sqrt{\pi / 2}} e^{\frac{-2\left(\delta-\delta_{0}\right)^{2}}{w^{2}}}
$$

where $\delta_{0}$ is the $\delta$ value associated with the distribution peak, $\mathrm{A}$ is a constant for a particular distribution curve and $w=\frac{\Gamma}{\sqrt{\ln 4}}, \Gamma$ being the full width at half maxima (FWHM) of the distribution curve. The data are fitted well to equation (1) for all the stages and the fitting parameters are shown in table-II. The $\delta_{0}$ values for different vitellogenic stages are found to tally well with the statistical mean of oocyte cell diameter for different stages shown in table I.

The peak value of the distribution $\left(\delta_{0}\right)$ is found to shift towards higher oocyte cell diameter with advancement of vitellogenesis process. The $\Gamma$ value of the distribution is found to be highest for the yolk granule stage of vitellogenesis. This observation can be attributed to the fact that the yolk granules begin to deposit in the yolk vesicles just after they are formed and it is a continuous but relatively slower process in comparison to the yolk vesicle formation and the conversion of the yolk granule stage into the mature oocyte stage.

\subsection{Dependence of $\zeta_{\mathrm{ZR}}$ and $\zeta_{\mathrm{ZG}}$ on $\delta$}

Figure 6 shows the variations in the heights of zona radiata layer $\left(\zeta_{\mathrm{ZR}}\right)$ and zona granulosa layer $\left(\zeta_{\mathrm{ZG}}\right)$ with increasing oocyte cell diameter $(\delta)$ during the vitellogenesis process in the case of Mystus vittatus. Analysis of covariance revealed linear dependence for both the layer heights on the oocyte cell diameter $(\mathrm{p}<0.001)$. The statistical significance level of $\mathrm{r}^{2}$ and the linear regression parameters $\alpha$ and $\beta$ are estimated by linear regressions on the linear equation of

$\zeta_{\mathrm{ZR}}=\alpha_{\mathrm{ZR}}+\beta_{\mathrm{ZR}} \delta \quad$ (2) for zona radiata layer

and

$\zeta_{\mathrm{ZG}}=\alpha_{\mathrm{ZR}}+\beta_{\mathrm{ZG}} \delta \quad$ (3) for zona granulosa layer.

Linear regression analysis $\left(r^{2}=0.961, p=0.0005\right)$ of the $Z G$ data to the equation (3) gives regression parameter values $\alpha_{\mathrm{ZG}}=6.87$ and $\beta_{\mathrm{ZG}}=0.014$. Again, for $\mathrm{ZR}$ layer the analysis $\left(\mathrm{r}^{2}=0.968, \mathrm{p}=\right.$ $0.0003)$ gives regression parameter values $\alpha_{Z R}=1.12$ and $\beta_{\mathrm{ZR}}=$ 0.015 .

From the regression parameters obtained from figure 6, it can be seen that though the $\beta$ values are almost same for both the layer heights, there exists significant difference in the values of $\alpha_{\mathrm{ZG}}(6.87)$ and $\alpha_{\mathrm{ZR}}$ (1.12). This indicates the fact that from yolk vesicle stage onwards, the value of $\zeta_{\mathrm{ZG}}$ is always higher than $\zeta_{\mathrm{ZR}}$ with increasing $\delta$. This is due to the fact that the $Z G$ is associated with the process of vitellogenesis [9] and hence, with the increase in the activity of the $\mathrm{ZG}$ the yolk materials are incorporated into the oocytic cytoplasm. But the ZR do not play any direct role in vitellogenesis except for the transportation of the vitellogenic materials across its pore canals [15], and the slight increase in its height is perhaps due its role in receptor mediated endocytosis [16] and its protective role in the aquatic environment; larger oocyte volume due to yolk incorporation demands larger or greater number of pore canals and greater mechanical support respectively and hence, increase in height or thickness of the ZR layer. However, the other functions of the ZR cannot be ignored [10]. 
Table. 1: Oocytic cell diameters in different vitellogenic stages measured from optical micrographs.

\begin{tabular}{cccccc}
\hline Name of the Stage & $\begin{array}{c}\text { Minimum Cell diameter } \\
(\boldsymbol{\mu} \mathbf{m})\end{array}$ & $\begin{array}{c}\text { Maximum Cell } \\
\text { diameter }(\boldsymbol{\mu} \mathbf{m})\end{array}$ & $\begin{array}{c}\text { Mean } \\
\text { Cell diameter }(\boldsymbol{\mu} \mathbf{m})\end{array}$ & Standard Deviation & Standard Error \\
\hline Late Perinucleolus & 78 & 110 & 91.9 & \pm 9.29 & \pm 1.31 \\
Yolk Vescicle & 130 & 215 & 185.14 & \pm 16.62 & \pm 2.35 \\
Yolk Granule & 305 & 480 & 416.25 & \pm 34.09 & \pm 4.73 \\
Mature Oocyte & 492 & 616 & 556.98 & \pm 19.23 & \pm 2.72 \\
\hline
\end{tabular}

Table. 2: Gaussian Fitting parameters for oocyte size distribution at $5 \%$ level of significance.

\begin{tabular}{ccccccc}
\hline Name of the Stage & $\boldsymbol{\delta}_{\mathbf{0}}(\boldsymbol{\mu} \mathbf{m})$ & $\mathbf{w}(\boldsymbol{\mu} \mathbf{m})$ & $\boldsymbol{\Gamma}(\boldsymbol{\mu} \mathbf{m})$ & $\mathbf{A}(\boldsymbol{\mu m})$ & $\chi^{2} / \mathbf{D O F}$ & $\mathbf{r}^{2}$ \\
\hline Late Perinucleolus & 94.53 & 15.02 & 26.64 & 273.40 & 0.493 & 0.999 \\
Yolk Vescicle & 189.12 & 9.30 & 16.49 & 306.08 & 1.874 & 0.974 \\
Yolk Granule & 424.88 & 16.77 & 29.75 & 276.18 & 1.702 & 0.900 \\
Mature Oocyte & 554.38 & 13.61 & 24.15 & 357.91 & 0.766 & 0.983 \\
\hline
\end{tabular}
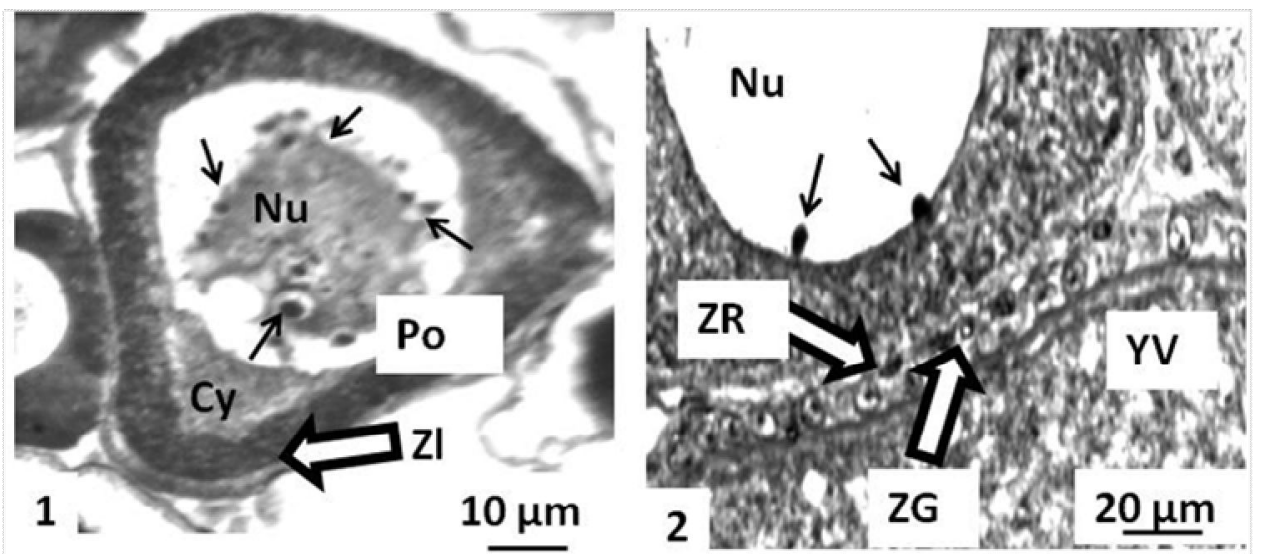

Fig. 1: Optical micrograph of the histological section of an ovary showing late perinucleolus oocyte (LPo) of Mystus vittatus with cytoplasm (Cy), a centrally placed nucleus $(\mathrm{Nu})$ and few nucleolus (arrows). Note the appearance of the zona layers (Zl). (IA); Figure 2: Optical micrograph of the histological section of a yolk vesicle stage of Mystus vittatus showing a nucleus ( $\mathrm{Nu}$ ) with nucleoli (arrows). Note the zona radiata (ZR) and zona granulosa (ZG) layers with syncitial nuclei. (IA)
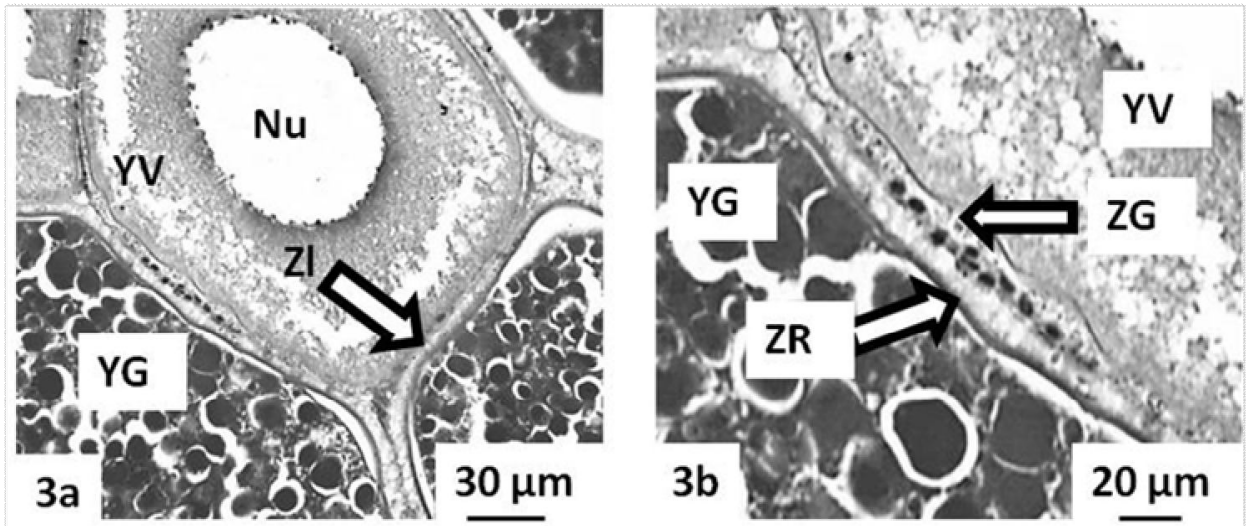

Fig. 3: Optical micrographs of the histological section of ovary in Mystus vittatus showing (a) a yolk vesicle stage (YV) with nucleus (Nu) and a yolk granule stage (YG). Note the thickened zona layers (Zl). (H \& E). (b) the zona radiata (ZR) and the Zona granulosa (ZG) layer with prominent syncitial nuclei. (H \& E) 

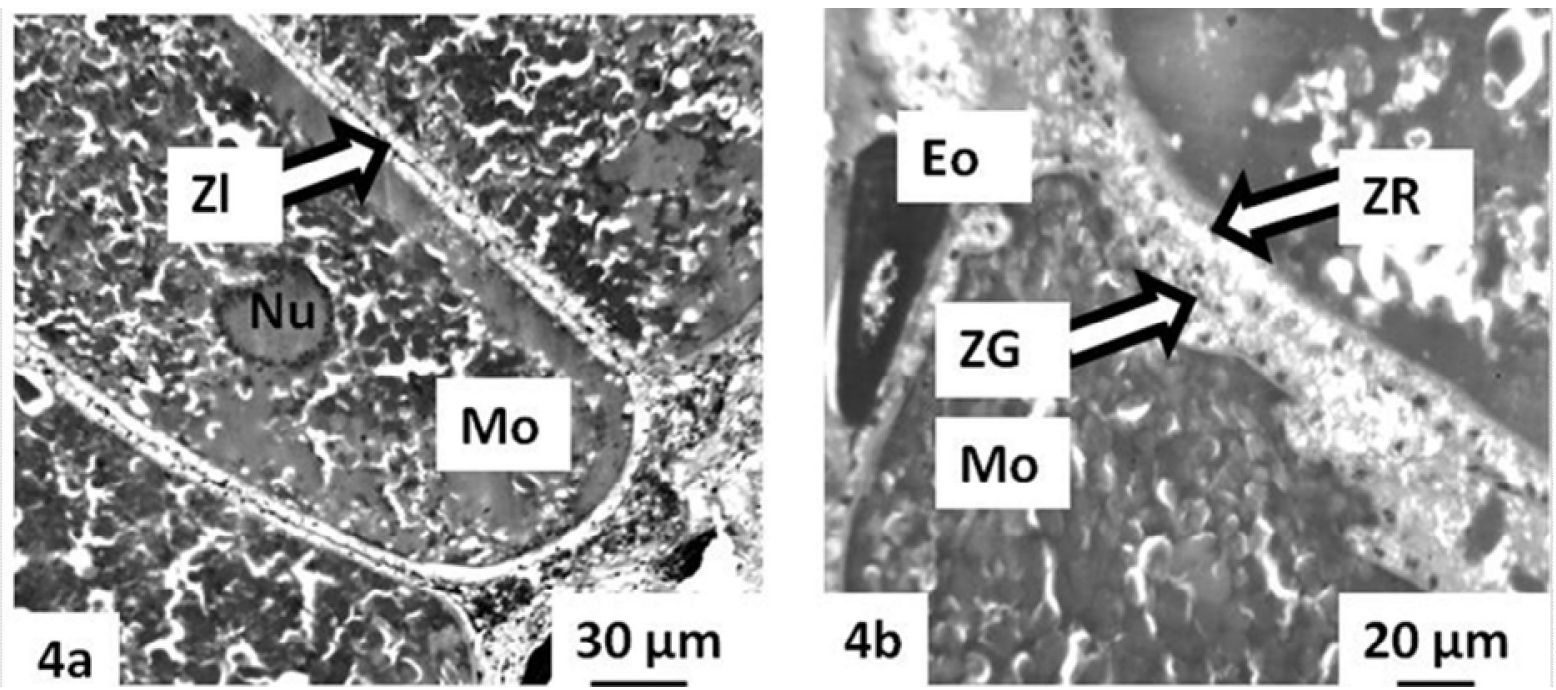

Fig. 4: Optical micrograph of the histological section of ovary in Mystus vittatus showing (a) mature oocyte with prominent eccentric nucleus. Note the zona layers (Zl) surrounding the oocyte. ( $\mathrm{H} \& \mathrm{E})(\mathrm{b})$ an early oocyte (Eo) and a mature oocyte (Mo). Note the thickened zona radiata (ZR) and the syncitial zona granulosa (ZG). (H \& E).
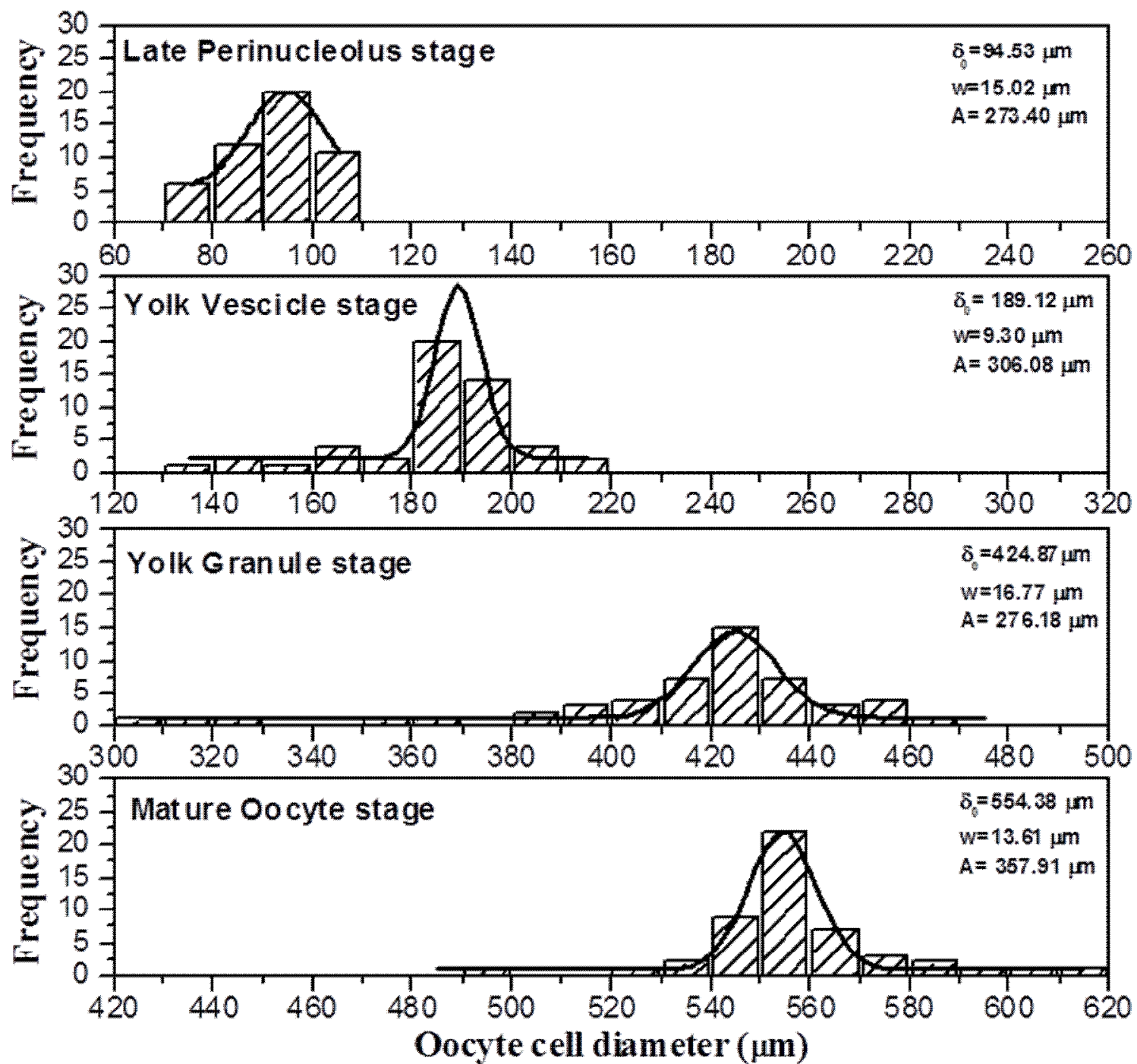

Fig. 5: Size distribution of the oocytic cells and corresponding Gaussian fitting curves for different vitellogenic stages in Mystus vittatus 


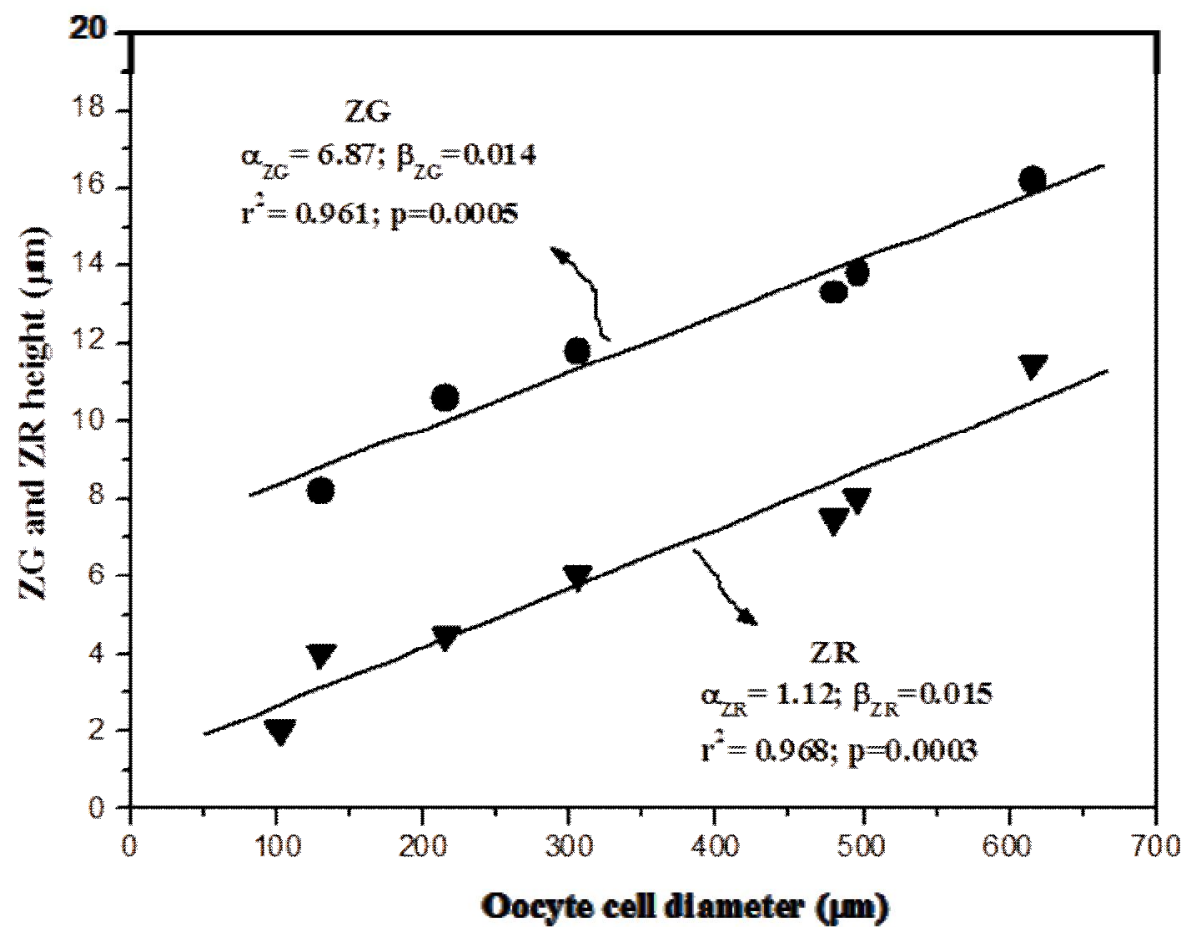

Fig. 6: Variation of the heights of zona radiata layer $\left(\zeta_{\mathrm{ZR}}\right)$ and zona granulosa layer $\left(\zeta_{\mathrm{ZG}}\right)$ with increasing oocyte cell diameter $(\delta)$ during the vitellogenesis process in Mystus vittatus.

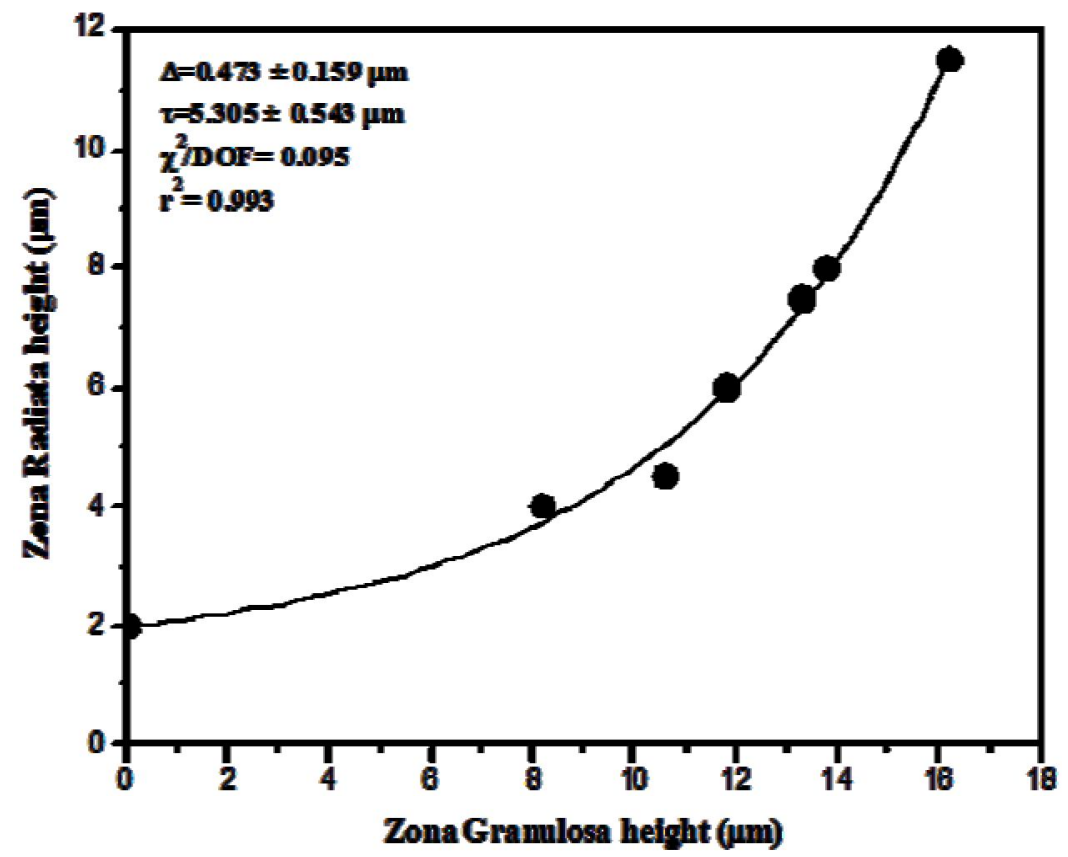

Fig. 7: Variation of the height of zona radiata layer $\left(\zeta_{\mathrm{ZR}}\right)$ with the height of zona radiata layer $\left(\zeta_{\mathrm{ZG}}\right)$ during different vitellogenic stages in Mystus vittatus. 


\subsection{Dependence of $\zeta_{\mathrm{ZR}}$ on $\zeta_{\mathrm{ZG}}$}

Figure 7 shows the variation of $\zeta_{\mathrm{ZR}}$ with $\zeta_{\mathrm{ZG}}$ during different vitellogenic stages. It can be noticed that the relation is non-linear and the data fitted well $\left(\chi^{2} / \mathrm{DOF}=0.095 ; \mathrm{r}^{2}=0.993\right)$ to the exponential growth curve

$$
\zeta_{Z R}=\Delta e^{\frac{\zeta_{Z G}}{\tau}}
$$

having fitting parameters $\Delta=0.473 \pm 0.159 \mu \mathrm{m}$ and $\tau=5.305 \pm$ $0.543 \mu \mathrm{m}$. This nature of dependence can be explained from the fact that the cells of $\mathrm{ZG}$ with prominent visible nuclei play active metabolic role during the process of vitellogenesis. On the other hand, ZR only acts as a permeable medium for the incorporation of yolk and enzymes inside the oocytic cytoplasm during vitellogenesis.

\section{CONCLUSION}

A quantitative approach is used to investigate the oogenesis process during vitellogenesis in Asian striped catfish Mystus vittatus. Analytic relationship between oocyte cell diameter and heights of zona layers during vitellogenesis has been proposed. Heights of both the layers are found to increase with oocytic cells diameters and showed linear dependence in the experimental range. The change in the height of zona radiata with the height of zona granulosa during vitellogenesis followed exponential growth of first order.

\section{ACKNOWLEDGEMENT}

One of the authors (N.C.) is thankful to the Eastern Regional Office of University Grants Commission, India. The authors are also thankful to the Department of Zoology, Ramananda College, Bishnupur, Bankura for giving the opportunity to use the laboratory during the tenure of this work.

\section{REFERENCES}

1. Rastogi RK. Studies on the oogenesis III. Vitellogenesis in some freshwater teleosts. Anat Anz. 1969; 125: 34-36.

2. Khanna SS, Sanwal R. Cyclic changes in the ovary of a fresh water teleost, Channa gachua. Zool Beiter. 1971; 17: 311-326.

3. Selman K, Wallace RA. Gametogenesis in Fundulus heteroclitus. Amer. Zool. 1986; 26: 173-192.

4. Manna PR, Bhattacharya S. Gonadotropin binding to the ovary of an Indian major carp, Catla catla at different stages of reproductive cycle. J. Biosciences. 1993; 18: 361-372.
5. Selman KR, Wallace A, Sarka QIX. Stages of oocyte development in the zebrafish, Brachydanio rerio, J. Morphol. 1993; 218: 203-224.

6. Singh A, Singh IJ, Ram RN, Kushwaha B. Ovarian development in Labeo dyocheilus (McClelland) during active reproductive phase under captive and wild conditions. J. Env. Biol. 2008; 29: 169-174.

7. Ferreira F, Santos MM, Reis-Henriques MA, Vieira NM. The annual cycle of oogenesis in the shanny, Lipophrys pholis. Sci. Marina. 2012; 76: 273-280.

8. Yin JX, Racey P, Li J, Zhang YG. The ovarian cycle of the fish Leptobotia elongata Bleeker, endemic to China. Pakistan J. Zool. 2012; 44: 997-1005.

9. Cruz-Höfling MA, Cruz-Landim C. Differentiation of the follicular epithelium during oocyte growth in the Amazonian fish, Crenicichla johanna (Teleostei: Cichlidae). Zool. Jb. Anat 1993; 23: 59-74.

10. Rizzo E, Godinho PH, Sato Y. Short-term storage of oocytes from the neotropical teleost fish Prochilodus marggravii. Theriogenology, 2003; 60: 1059-1070.

11. Ross N, Islam M, Thilsted SH. Small indigenous fish species in Bangladesh: Contribution to Vitamin A, calcium and iron intakes, J. Nutr. 2003; 133: 4021-4026.

12. Costa AC, Chaves PR. Manual de técnica histological Guia de trabalhos práticos. Portugália Editora, Lisboa. 1943; 544 pp.

13. Chakrabarti $\mathrm{P}$, Chatterjee N. Histological changes in the activity of the thyroid follicles and its impact on ovarian tissues in Mystus vittatus (Bloch, 1794) during growth, maturation and spawning phases. Cibtech J. Zoo. 2014; 3(1): 27-36.

14. Brandão CAS, Valentim MFM, Caramaschi EP. Ovary maturation stages and oocyte features in three species of the Neotropical fish Hemiodus (Muller, 1842), Braz. Arch. Biol. Technol. 2003; 46: 433-441.

15. Shabanipour N, Heidari B. A histological study of the zona radiata during late oocyte developmental stages in the Caspian sea mugilid, Liza aurata (Risso 1810), Braz. J. Morphol. Sci. 2004; 21(4): 191-195.

16. Evans HD. The physiology of fishes In: Reproductive Physiology (Redding J, Reynaldo P, eds), CRC Press, Inc.: USA. 1993; pp. 503-534.

\section{How to cite this article:}

Nilanjana Chatterjee and Baibaswata Bhattacharjee. Oocyte Developmental Stages and its Relationship with the Zona Layers During Vitellogenesis in the Asian Striped Catfish Mystus vittatus (Bloch, 1794). J App Biol Biotech, 2014; 2 (04): 001-006. 